\title{
LOS PRECIOS DE LOS BIENES EN LAS FRONTERAS BRAVÍAS DEL RÍO DE LA PLATA COLONIAL: SANTA FE DURANTE LA PRIMERA MITAD DEL SIGLO XVIII
}

\section{PRICES OF GOODS IN THE WILD BORDERLANDS OF COLONIAL RIO DE LA PLATA REGION: SANTA FE DURING THE FIRST HALF OF THE XVIII CENTURY}

\author{
Julio Djenderedjian y Juan Luis Martirén* \\ Universidad de Buenos Aires, Buenos Aires, Argentina, \\ <juliodjend@yahoo.com.ar>; <jlmartiren@hotmail.com>
}

\begin{abstract}
Resumen. La historia de los precios en el Río de la Plata colonial, más allá de valiosos aportes, tiene aún grandes deficiencias. Una de ellas es la falta de series para ciudades interiores de dimensión menor y de frontera. En este trabajo presentamos series de precios de un espectro bastante amplio de bienes de uso y de consumo correspondientes a la ciudad de Santa Fe para la primera mitad del siglo XVIII, justamente una etapa caracterizada por constantes ataques indígenas. Se estudian las tendencias de largo plazo en la evolución de los precios y el impacto de la situación bélica en la economía local, realizándose en paralelo algunas comparaciones con las series existentes para otras ciudades de este espacio. Las conclusiones indican que la situación bélica no implicó distorsiones muy significativas en el largo plazo, aunque sí en coyunturas puntuales.
\end{abstract}

Palabras clave: historia de precios, espacio rioplatense, frontera.

Abstract. Price history of colonial Río de la Plata region, despite valuable contributions, has still major shortcomings. Among them, is the lack of series for minor cities and borderland areas. This article presents and analyzes the evolution of prices in Santa $\mathrm{Fe}$ city during the first half of the XVIII Century, a period full of Indian attacks. We study the long-run trends in prices, and the impact of war on the local economy. Besides, some comparisons have been done with the extant price series from other neighboring cities. Conclusions show that, in the long run, warfare did not bring major problems, but it did in particular moments.

Key words: price history, River Plate economy, frontier.

Fecha de recepción: abril de 2012. Fecha de aceptación: agosto de 2012.

* Los autores agradecen los comentarios de los evaluadores anónimos a una versión previa de este artículo.

Am. Lat. Hist. Econ., año 20, núm. 2, mayo-agosto, 2013, pp. 36-66 


\section{INTRODUCCIÓN}

$\mathrm{E}$ 1 actual auge de los estudios sobre el nivel de vida presta renovado interés a las series de precios de factores de bienes de uso y de consumo, necesarios para el cálculo de canastas básicas y evolución del poder de compra del salario; la sofisticación creciente del análisis ha derivado en el surgimiento de series de precios minoristas de "segunda generación", esto es, más certeras, amplias y cercanas al gasto diario de la población que las antiguas series de materias primas o de insumos al por mayor. ${ }^{1}$ Multitud de aspectos clave, como los cambios en la forma misma de pensar el consumo o las consecuencias sociales de las alteraciones en los niveles relativos de los precios en tiempos preindustriales, dan nuevos alicientes y justificativos a los avances al respecto para periodos preestadísticos. ${ }^{2}$ Por lo demás, la tradicional construcción de series para núcleos de importancia económica o política -en esencia, las ciudades de mayor dimensión-, ha ido dejando paso al convencimiento de que es necesario contar con más y mejores series que den cuenta de la evolución del costo de bienes y servicios en ciudades menores o ámbitos rurales, como único camino para medir y estudiar con mayor certeza los hechos económicos que afectaron al conjunto. De modo que la vigencia de la historia de los precios no sólo está demostrada por la necesidad de cubrir con sustancia empírica una multitud de aspectos clave de la economía de los últimos siglos, sino por el dinamismo que la propia investigación aporta al debate, haciendo surgir preguntas originales a partir de la comparación de los resultados de nuevas series de datos o de nuevas miradas sobre las que ya poseíamos. ${ }^{3}$

Entre las deficiencias actualmente existentes en el panorama de la historia económica rioplatense, una de las más acuciantes gira en torno a la falta de series confiables y completas de precios de bienes y factores. El periodo anterior a 1900 es, en Argentina, especialmente crítico en varios aspectos. Si bien contamos con diversas series de precios de buena o aun excelente calidad, estas a menudo poseen en el largo plazo grandes claros que dificultan la comprensión de los procesos económicos. Por otro lado, sólo se ha cubierto un haz reducido de bienes, factores y servicios, y apenas para las dos ciudades más importantes, Buenos Aires y Córdoba. ${ }^{4}$ En

\footnotetext{
${ }^{1}$ Cuyas variaciones no necesariamente son proporcionales a las de los precios de los bienes de consumo, como nos lo recuerda Nordhaus, "Real-Output", 1996, pp. 55 y ss., y Hoffman et al., "Real", 2002.

${ }^{2}$ Véase Vries, "Between", 1993, pp. 85 y ss.

${ }^{3}$ Entre muchos otros, Allen et al., "Wages", 2011; Broadberry y Gupta, "Early", 2005; Dobado y García, "Neither", 2012, y Llopis y García, "Cost", 2007.

${ }_{4}^{4}$ Para Buenos Aires, Álvarez, Temas, 1929; Johnson, "Salarios”, 1990; Garavaglia "Precios", 1995; Cuesta, Precios, 2009; para Córdoba, Arcondo, Ocaso, 1992, entre otros.
} 
los casos en que contamos con series seculares para un mismo producto, las mismas no son necesariamente compatibles. Por ejemplo, existen buenas series de precios del trigo para Buenos Aires desde 1700 hasta 1900; pero las de la época colonial son minoristas, mientras que las del siglo XIX son mayoristas. ${ }^{5}$ Resumiendo, más allá de los valiosos esfuerzos realizados, una parte de lo existente se compone de series de precios de primera generación, de alcance geográfico limitado, no homogéneas, de plazo corto y parcialmente incompletas. Agreguemos a ello los problemas de conversión a valores uniformes, dadas las disímiles unidades monetarias en que están expresados los datos, y las variaciones en la ley del metal. Es por tanto necesario no sólo completar o prolongar varias de las series existentes, sino revisarlas y elaborar otras nuevas, y más aún avanzar sobre la terra incognita que significa hoy el interior del actual país. El problema se vuelve más apremiante a medida que se retrocede en el tiempo: para épocas anteriores al virreinato puede decirse que la historia económica rioplatense está en buena parte todavía en las sombras, por tanto la necesidad de contar con series de precios se vuelve mayor.

En este trabajo presentamos y analizamos series de precios de un espectro bastante amplio de bienes de uso y de consumo correspondientes a la ciudad de Santa Fe para la primera mitad del siglo XVIII. Este caso y periodo resultan especialmente importantes por ser Santa Fe un nudo crucial del tráfico rioplatense entre Paraguay, las misiones jesuíticas, Buenos Aires y el interior, y entre este y el mundo atlántico. Era asimismo una de las ciudades más importantes del área, a pesar de su escasa dimensión; luego de Buenos Aires y Córdoba, sólo la superaban algunas de las viejas ciudades del lejano noroeste, que contaban con población indígena. ${ }^{6}$ Pero además, se trataba de una población de frontera, que conoció en esos años duras coyunturas críticas, pautadas por amenazantes avances indígenas y erráticos ciclos comerciales; a pesar de ello, la ocupación de la orilla opuesta del río Paraná, y el surgimiento de la hoy ciudad homónima emplazada allí, son indicios de que aun dentro del marasmo y los problemas existieron momentos de expansión económica. Contamos con los libros

\footnotetext{
${ }^{5}$ Aclaremos que las del siglo XIX no están completas. Más allá de ello, existen diferencias en la oferta, que en el caso del trigo de Buenos Aires hasta aproximadamente 1820 se componía de trigo cosechado en la costa rioplatense a partir de semillas tradicionales; luego, va incorporando trigos y sus subproductos llegados desde el exterior (Chile, Estados Unidos) o el interior (Mendoza, Córdoba, las fronteras bonaerenses). Y posteriormente se agregarán los trigos de las colonias agrícolas de Santa Fe y Entre Ríos, que incluyen variedades distintas de las criollas (Barletta, Saldomé, francés).

${ }^{6}$ Es la situación, por ejemplo, de Santiago del Estero o Salta. De todos modos, aun en sus momentos de nadir demográfico, Santa Fe parece haber continuado manteniendo un digno cuarto lugar entre las ciudades que por entonces conformaban lo que luego sería Argentina. Véase Comadrán, Evolución, 1969, pp. 43-51.
} 
de cuentas del colegio jesuítico de Santa Fe, que registran en forma detallada y sistemática los precios de diversos bienes comprados para el abasto tanto de esa casa religiosa como de las estancias que poseía, y las ventas de la producción de estas, que se limitaban a ganado en pie y, muy esporádicamente, algunas partidas de trigo. ${ }^{7}$ Por tratarse el colegio santafesino de una pieza clave en el entramado comercial jesuítico, figuran asimismo múltiples partidas de bienes traídos desde las misiones guaraníes (yerba, lienzo), a fin de distribuirlos por el resto del espacio virreinal, o aun desde otras casas de la orden (vino de Córdoba, por ejemplo). Son de registros diarios en los que se asentaron partidas individuales por cada una de las compras o ventas efectuadas, variando estas desde unas pocas unidades a cantidades considerables. Al finalizar el mes correspondiente, se escribía el nombre del nuevo y se continuaban las anotaciones; ello, y los cambios frecuentes en la letra y la tinta, indican que se trata de un registro original y no de transcripciones. Se salvaron los errores, por lo demás poco numerosos, y se descartaron los datos incongruentes, que tampoco fueron demasiados. $^{8}$

Mientras que ciertos bienes han sido enajenados en cantidades de magnitud en principio demasiado grande como para transacciones destinadas al consumo diario de grupos reducidos -el trigo por fanegas santafesinas de 375 libras; la yerba por arrobas y no por libras; el tabaco por arrobas y no por mazos; la harina por fanegas-, otros sí lo son -la ropa por varas, el papel por resma, la cera por libras-, en tanto que otros son indivisibles -como el ganado, obviamente graduado por unidad. ${ }^{9}$ Pero ello no necesariamente significa que algunos de nuestros precios sean al detalle y otros no. Es decir, si bien productos como el lienzo, la ropa, el ruán, la cera, la bayeta o el papel figuran graduados en medida minorista, no poseemos otros registros de precios al menudeo que nos permitan saber con seguridad si sus precios en la fuente jesuítica lo estaban también o no. ${ }^{10}$ Aun figurando en entregas a todo tipo de personas, incluso a simples peones de la estancia, y en cantidades también muy variables, los precios son siempre similares cuando se comparan operaciones realizadas con escasa diferencia de tiempo. ${ }^{11}$ Por otro lado, varios indicios apuntan a

${ }^{7}$ El cuaderno se encuentra en Archivo Histórico de la Provincia de Santa Fe, Santa Fe, Argentina (en adelante AHPSF), Contaduría, t. 6, 1707-1748 y 1733-1749.

${ }^{8}$ Entre unos y otros, 72 sobre 3985 entradas o 1.8 por ciento.

${ }^{9}$ Téngase en cuenta que la fanega de trigo santafesina tenía un peso que era alrededor de 80\% mayor a la bonaerense, de sólo 210 a 215 libras. Napp, República, 1876, pp. 368-369.

${ }^{10}$ Es oportuno apuntar aquí que Arcondo, quien utilizó para sus series de Córdoba una fuente del mismo origen y muy similar a la nuestra, asume que los precios de la misma son minoristas. Lo mismo ocurre con la fuente de Cuesta para Buenos Aires, aunque de otra orden religiosa.

${ }^{11}$ Respecto al ganado, cabe aclarar que, más allá de que los precios son por unidad, las cantidades transadas y la falta de diferenciación por calidad individual indican que las transacciones 
que en nuestra fuente, aun en las operaciones de poca entidad y graduadas en medida minorista, los precios podrían estar más cercanos a rangos mayoristas que minoristas. ${ }^{12} \mathrm{Si}$ bien, como veremos, las diferencias entre precios al detalle y al mayoreo podían ser altas, el problema en realidad era que las transacciones al detalle efectuadas por dinero debían ocupar un espectro muy reducido en la economía local, por lo que los registros de las mismas son extremadamente escasos. ${ }^{13}$ De cualquier forma, dado que estudiaremos las tendencias en el largo plazo por grupos de productos según su origen, presuponemos que las diferencias entre precios minoristas y mayoristas no afectarán el análisis, ya que podemos postular que ambas curvas debieran en definitiva ser solidarias. Optamos así por presentar los números originales completos de las series en el anexo de este artículo (en reales de plata de 3.38 gramos del sistema métrico), y utilizar en el cuerpo del artículo los datos de las mismas aun cuando no podamos estar completamente seguros de que todas ellas sean mayoristas. ${ }^{14}$

Las series que hemos obtenido resultarán así útiles para comprender mejor la historia económica del área rioplatense de la primera mitad del siglo XVIII, para estudiar las tendencias de largo plazo y el impacto de la situación bélica en la economía local, así como para establecer algunas comparaciones entre las tres ciudades más importantes de esa área -Santa Fe, Córdoba y Buenos Aires. Las mismas estaban ligadas por el camino que unía a Buenos Aires, puerto atlántico, con el Alto Perú; en los entornos

en nuestra fuente son al mayoreo. Aparte del ganado, en los casos de operaciones por cantidades considerables pero registradas en unidades de medida minorista, los precios transados presentaron en general homogeneidad con los correspondientes a partidas menores (los pocos casos discordantes han sido descartados). Los libros de cuenta ofrecen a menudo precios de un mismo producto en unidades de medida distintas; por ejemplo, en el de los jesuitas hay registros de aceitunas por almud y por botija, o de porotos por almud y por fanega. Pero no hay allí diferencias sustanciales de precio en esas operaciones si las reducimos a unidades homogéneas.

${ }^{12}$ Es posible que las ventas reflejaran una política específica de la Compañía de Jesús, que buscaba al parecer su ganancia en el tráfico entre las distintas regiones y no a escala local; en Paraguay, por ejemplo, los administradores de una estancia jesuítica tramitaban encargos de productos importados para sus esclavos; al recibirlos, estos se ponían "locos de contentos, viéndose con tantas cosas por su poco de tabaco". Es decir, sin duda los precios a los que recibían esos bienes eran sustancialmente menores a los que esos mismos bienes les eran cobrados por otros comerciantes locales que se los venderían al detalle permutándolos por su valor en el tabaco que esos esclavos producían en sus siembras particulares. Telesca, Expulsos, 2009, p. 136. Esa política de la Compañía bien podría atribuirse a incentivos para fidelizar a sus empleados; su escala regional y aun continental le permitía sin dudas vender a precios si no mayoristas al menos muy inferiores a los minoristas, cosa que explicaría también la mala fama de los jesuitas entre los comerciantes locales.

13 "Tan poco dinero existe entre las gentes vulgares[...] que en la mayor parte[...] se trueca una cosa por otra." Paucke, Hacia, 1942-1944, t. I, p. 143.

${ }^{14} \mathrm{El}$ real (de a ocho por un peso) circulante durante el periodo tallaba a 68 por marco de Castilla; era de peso de 67 13/17 granos, o 3383 gramos del sistema métrico; y ley de diez dineros 20 granos, o 902777 milésimos. Burzio, Diccionario, 1958, t. II, p. 293. 
rurales de las tres se producían diversos bienes destinados a satisfacer necesidades de los núcleos mineros, en especial de Potosí. Esas tres ciudades están situadas a una distancia no demasiado grande entre sí, al menos para los parámetros americanos. ${ }^{15}$ De todos modos, debido a la falta de espacio, no profundizaremos en este artículo en esa comparación, que abordaremos en forma integral en otra ocasión.

Además de la fuente jesuítica ${ }^{16}$ se revisaron los libros de cuentas de la Orden de La Merced, en cuyo convento de Santa Fe también se registraron los precios y cantidades de los bienes comprados para la cocina comunal y las necesidades de vestuario y servicio de los religiosos. Esos registros, que arrancan en 1690 y llegan hasta 1835 , cubren con detalle el periodo 1699-1778, y con gran calidad los años comprendidos entre 1706 y 1751, salvo en lo que respecta, en algunos de ellos, a ciertos bienes recibidos como limosna. ${ }^{17}$ Se trata de una fuente muy similar a la que hemos utilizado aquí. Al comparar muestras de ambos registros (jesuíticos y mercedarios) los precios obtenidos para los mismos bienes en los mismos periodos se mostraron coincidentes; por ello no se avanzó en la transcripción e integración de los datos del convento de La Merced, aspectos que se tratarán más adelante, utilizándose en este artículo sólo los datos jesuíticos. La incorporación de los datos de La Merced, y eventualmente los de San Francisco, ayudará sin duda a completar y continuar las series en el tiempo. En principio, de todo el conjunto hemos seleccionado series de productos cuyos precios estuvieran representados adecuadamente a lo largo de todo el periodo con datos (1707-1747). Establecimos así cinco categorías:

Precios A: datos útiles de cinco o más entradas por año, razonablemente distribuidas a lo largo de los diferentes meses. Los precios obtenidos cubren todos los años de la serie.

Precios B: datos útiles de cinco o más entradas por año razonablemente distribuidas a lo largo de los diferentes meses; no obstante, en la serie de 41 años se toleró la existencia de hasta diez años con mínimos de tres a cinco entradas. Los precios obtenidos no cubren todos los años de la serie, existiendo una tolerancia máxima de $10 \%$ del total de años sin datos.

Precios C: datos útiles de cinco o más entradas por año, tolerando la existencia de entre 10 y 20 años de la serie con tres a cinco entradas. Los

\footnotetext{
${ }^{15}$ Santa Fe se encuentra a unos 475 kilómetros al norte de Buenos Aires y a 330 kilómetros al este de Córdoba.

${ }^{16}$ La cual es de gran utilidad porque tiene el mismo origen que la utilizada por Arcondo para los precios de Córdoba durante el mismo periodo; y es de similar carácter a las cuentas de Santo Domingo empleadas por Cuesta para Buenos Aires, o las de varios conventos que utilizó Johnson. Véanse Arcondo, Ocaso, 1992; Cuesta, Precios, 2009, y Johnson, "Salarios", 1990.

${ }^{17}$ Archivo de la Orden de La Merced, Córdoba, Argentina (AOLM), libros de ingresos y gastos del Convento de San Agustín, Santa Fe, Argentina.
} 
precios obtenidos no cubren todos los años de la serie, existiendo una tolerancia máxima de $25 \%$ del total de años sin datos.

Precios D: datos útiles de cinco o más entradas por año, tolerando la existencia de hasta 20 años de la serie con tres a cinco entradas. Los precios obtenidos no cubren todos los años de la serie, existiendo una tolerancia máxima de 40\% del total de años sin datos.

Precios E: datos útiles de menos de cinco entradas por año en más de $50 \%$ del total de años cubiertos. Los precios obtenidos no cubren todos los años de la serie, existiendo una tolerancia máxima de $40 \%$ del total de años sin datos.

La razón de incluir los precios $\mathrm{E}$, que podrían no considerarse suficientemente sólidos, responde a que, comparándolos a partir de muestras con los datos provenientes de los libros de gastos e ingresos de La Merced, evidenciaron consistencias bastante significativas como para postular que, cuando contemos con series más completas, estas no diferirán sustancialmente de las ya obtenidas. Otros productos de los libros santafesinos no pudieron en cambio ser incorporados dada la falta de datos. ${ }^{18}$ No se cubrieron tampoco los faltantes de estas series originales, pero sí se lo hizo mediante interpolación en las de índices, como veremos (cuadro 1).

Las series se clasificaron en locales, regionales y ultramarinas, correspondiendo a productos de esos orígenes. ${ }^{19}$ Se consideraron productos locales a aquellos que sabemos se originaban en la misma ciudad de Santa Fe o en su espacio rural circundante (harina, trigo, grasa, ganado); regionales a aquellos que provenían de otras áreas del virreinato (tabaco, yerba y lienzo de Paraguay o de Misiones; aguardiente y vino de Córdoba, Mendoza y San Juan; sal de las salinas pampeanas o cordobesas; cera de Santiago del Estero), y ultramarinos a los traídos desde Europa (papel, textiles de calidad).$^{20}$ Los bienes traídos de Córdoba se producían a menudo en las estancias de la Orden situadas allí; pero los precios son los mismos que los comprados localmente a otros proveedores. Dichos valores se ponderaron en razón de la cantidad transada mensualmente, y se obtuvieron promedios anuales a partir de los precios promedio mensuales. Todos los regis-

\footnotetext{
${ }^{18}$ Es de destacar que la fuente jesuítica registra precios de más de 200 productos de consumo y de uso, que fueron relevados y transcritos en su totalidad, aunque muchos de ellos fueron luego descartados por debilidad de las series o por no tratarse de bienes básicos (por ejemplo alcaparras, plomo, encajes de oro falso, paños franceses, de Castilla, de Londres o de Segovia, seda de Murcia, listonería de Génova, vino de Italia, peltre, etc.). De cualquier modo, parte del trabajo ya realizado ampliará el espectro de bienes cuando se incorporen los datos de otras fuentes.

${ }^{19}$ Esta útil discriminación, retomada luego por otros investigadores, fue propuesta por $\mathrm{Ar}$ condo en su trabajo de tesis de 1968. Véase Arcondo, Ocaso, 1992.

${ }^{20}$ Además de las circunstancias obvias, las adscripciones de cada producto a ámbitos locales, regionales o ultramarinos está confirmada por las fuentes y la bibliografía; véase Cervera, Historia, 1907 , t. I, pp. 445 y ss.
} 
CUADRO 1. PRECIOS DE BIENES DE USO Y DE CONSUMO, SANTA FE, 1707-1747. DETALLE DE LAS SERIES OBTENIDAS Y SU CLASIFICACIÓN

$\begin{array}{lll}\text { Precio } & \text { Bien de uso y consumo } & \text { Ámbito territorial } \\ \text { A } & \text { Yerba (arroba) } & \text { Regional } \\ \text { A } & \text { Tabaco (arroba) } & \text { Regional } \\ \text { A } & \text { Vino (botija) } & \text { Regional } \\ \text { B } & \text { Lienzo (varas) } & \text { Regional } \\ \text { B } & \text { Ropa (vara) } & \text { Regional } \\ \text { B } & \text { Vacas (unidad) } & \text { Local } \\ \text { C } & \text { Azúcar (arroba) } & \text { Regional } \\ \text { C } & \text { Carneros (unidad) } & \text { Local } \\ \text { C } & \text { Trigo (fanega) } & \text { Local } \\ \text { C } & \text { Grasa (botija) } & \text { Local } \\ \text { D } & \text { Ruán (vara) } & \text { Ultramarino } \\ \text { D } & \text { Harina (fanega) } & \text { Local } \\ \text { D } & \text { Sal (fanega) } & \text { Regional } \\ \text { E } & \text { Cera de Santiago (libra) } & \text { Regional } \\ \text { E } & \text { Bayeta (vara) } & \text { Ultramarino } \\ \text { E } & \text { Caballos (unidad) } & \text { Local } \\ \text { E } & \text { Aguardiente (botija) } & \text { Regional } \\ \text { E } & \text { Papel (resma) } & \text { Ultramarino }\end{array}$

${ }^{a}$ Bajo esta denominación entran partidas que incluyen reses, vacas y toros. Aparentemente son sinónimos para el escribiente. No hay gran dispersión de precios. No se incluyeron los bueyes, que sí tienen precios mucho más altos.

${ }^{\mathrm{b}}$ Sólo se trata de carneros, no corderos, que en todos los casos tenían un precio más bajo y no siempre reflejado por unidad, por lo que fueron descartados.

"Vale la misma aclaración que para "vacas" respecto a la edad, la capacidad y la calidad de los distintos animales, todos incluidos bajo la misma denominación. La dispersión de los precios no es sin embargo tampoco muy alta, lo cual sugiere que se trata de bienes homogéneos, ya que sabemos por otras fuentes que la diferencia de precios entre equinos de distinta calidad o atributos podía ser muy grande (variando incluso de 1 a 20 pesos). Yeguas y mulas no se incluyeron aquí sino que se conformaron para ellas series específicas, aunque las mismas no pudieron ser incluidas en este trabajo por escasez de masa crítica de datos.

Fuente: AHPSF, Contaduría, t. 6, 1707-1748 y 1733-1749.

tros se asentaron en reales (a ocho por un peso de plata), no existiendo en el periodo problemas de debasement. ${ }^{21}$

Dada la falta de espacio, el hecho de que aún no contemos con series de salarios, y que podríamos ampliar la lista de bienes informados con la

${ }^{21}$ Que ocurrirán al alterarse la ley en milésimos de fino de las monedas acuñadas a partir de 1772. Al respecto véase Romano, Moneda, 1998, p. 120. 
incorporación de los datos de los libros de otros conventos, optamos por no calcular el valor de una canasta de bienes ni la evolución del costo de vida. La obtención de series de "segunda generación", esto es, bienes de consumo directo con precios minoristas, presenta aquí diversos problemas; no parecen existir registros sistemáticos de mediano o largo plazos de productos tan básicos como el pan, aun cuando sí puedan construirse para algunos de ellos (frutas, conservas). Una muestra de las diferencias existentes entre precios de bienes de consumo comprados al mayoreo, tomados de nuestras cuentas, y al por menor, de otra fuente, puede resultar ilustrativa, incluso cuando tampoco la muestra minorista esté exenta de problemas (véase cuadro 2 ) ${ }^{22}$

Como puede observarse, las diferencias rondan entre 50 y $80 \%$, esto es, son bastante superiores a lo que sabemos era usual en estos casos, al menos en periodos algo posteriores, por lo que quizá aquí esté pesando sustantivamente la incertidumbre provocada por la situación de guerra o la circunstancia de que, en una economía donde el dinero contante era un bien muy raro, la mayoría de esos precios minoristas corresponda en realidad a bienes entregados al fiado, es decir, incorporando un spread a fin de compensar el riesgo de los incobrables y la tasa de interés por el plazo a transcurrir hasta el cobro. ${ }^{23}$

\section{LOS PRECIOS EN UNA ECONOMÍA DE FRONTERA ASEDIADA}

Como se mencionó, la ciudad de Santa Fe, fundada en 1573, constituía un núcleo para el comercio en las rutas entre Lima, Asunción y Buenos Aires. Las primeras décadas de vida de esta ciudad se caracterizaron por grandes dificultades relacionadas con la presión de los ataques indígenas desde la región chaqueña que llevaron a transplantar el casco urbano a catorce leguas al sudoeste del sitio original. ${ }^{24}$ Pero a la vez se trataba de un punto de importancia estratégica, que debía por tanto conservarse. La ventaja que

${ }^{22}$ En efecto, se trata de datos transcritos por Cervera, Historia, 1907, t. I, p. 436, es decir, de segunda mano, y sin indicación de fuente. Es muy probable sin embargo que hayan sido tomados de acuerdos del Cabildo, por lo que en todo caso podría no tratarse de precios de mercado. Además, Cervera no nos informa la fecha exacta -sólo el año- por lo que tampoco podemos estar seguros de que no hayan variado en forma sustancial a lo largo del mismo. Esas variaciones pudieron haber sido amplias, entre otras cosas a causa de la situación de guerra.

${ }^{23}$ Véase Djenderedjian, “Reevaluación”, 1998; en el caso allí estudiado, una localidad yerbatera paraguaya de inicios del siglo XIX, la diferencia entre precios mayoristas y minoristas era de $20 \%$, pero la correspondiente a bienes entregados al fiado y vendidos al menudeo rondaba de 30 a $40 \%$. No puede desde ya descartarse la existencia de una oferta oligopólica, situación muy frecuente en economías mercantiles; pero no parece que ello justifique por completo esa diferencia.

${ }^{24}$ Un interesante estudio sobre este espacio en el siglo XVIII en Suárez y Tornay, "Poblaciones", 2003. 


\section{CUADRO 2. PRECIOS MAYORISTAS Y MINORISTAS \\ DE DIVERSOS BIENES DE CONSUMO. SANTA FE, 1714}

\begin{tabular}{lllccc}
\hline Bien & $\begin{array}{c}\text { Medida } \\
\text { minorista }\end{array}$ & $\begin{array}{c}\text { Medida } \\
\text { mayorista }\end{array}$ & $\begin{array}{c}\text { Valor } \\
\text { minorista } \\
\text { (reales) }\end{array}$ & $\begin{array}{c}\text { Valor } \\
\text { mayorista } \\
\text { (reales) }\end{array}$ & $\begin{array}{c}\text { Diferencia } \\
\text { (porcentajes) }\end{array}$ \\
Miel & Cuartillo & Arroba & 24 & 64 & 50 \\
Pasas de uva & Libra & Arroba & 2 & 28 & 79 \\
Jabón blanco & Libra & Arroba & 2 & 28 & 79 \\
Yerba & Libra & Arroba & 1 & 16 & 56 \\
Tabaco & Libra & Arroba & 2 & 32 & 56 \\
\hline
\end{tabular}

Se trata de arrobas de 25 libras o de cuatro cuartillos.

Fuente: precios mayoristas en AHPSF, Contaduría, t. 6, 1707-1748 y 1733-1749, y minoristas en Cervera, Historia, 1907, t. I, p. 436.

otorgaba su control de la principal vía fluvial del espacio rioplatense había permitido el desarrollo de varios establecimientos ganaderos, nuevos curatos y "pagos" donde interactuaban vecinos hacendados, ocupantes y algunas estancias jesuíticas. Ello permitió una limitada y por momentos oscilante expansión de las áreas circundantes a la ciudad, que sin embargo recién comenzaría a consolidarse durante la segunda mitad del siglo XVIII. ${ }^{25}$ No contamos con censos poblacionales de Santa Fe anteriores a 1869, y sólo existen datos estimativos para 1760 y $1797 .{ }^{26}$ No podemos, por tanto, efectuar cálculos medianamente certeros sobre la población existente en la primera mitad del siglo XVIII, y menos aún evaluar los fuertes cambios que debieron tener lugar en medio de las luchas con los indígenas de ese periodo. Lo poco que puede decirse es que, según los historiadores, hacia finales del siglo XVII existían allí unos 270 vecinos, o alrededor de 1300 habitantes; para 1719, los reveses de la guerra de fronteras, en ese entonces en un momento álgido, parecen haber provocado la huida de varios vecinos con sus familias, de suerte que sólo quedaban unos 300 hombres de armas, lo que implicaría una cifra aún menor de vecinos. En esas dos décadas el crecimiento poblacional neto habría sido nulo o negativo, y todavía hacia 1750, luego de algunos años de relativa paz, la ciudad apenas contaba con una dimensión demográfica similar a la de medio siglo

${ }^{25}$ Ibid., pp. 523 y ss.

${ }^{26}$ Maeder, "Población", 1976, informa 1500 habitantes para la ciudad y 6356 para toda la jurisdicción en 1760, y Azara, Voyages, 1809, t. II, pp. 338-339, indica 4000 sólo para la ciudad, aunque esta cifra pudo incluir las áreas circundantes. 
atrás. ${ }^{27}$ Las razones de ese magro panorama estriban en que, desde inicios del siglo XVIII y hasta las paces generales con los guaycurúes, firmadas en 1746-1747, Santa Fe sufrió una devastadora serie de invasiones indígenas. El previo periodo de expansión, en el que se habían ocupado nuevas tierras, fue drásticamente revertido; según los testimonios, la ciudad misma permaneció en esos años bajo asedio. ${ }^{28}$ Es una exageración pensar que ese asedio fuera unánimemente sostenido durante las casi cuatro décadas que corren entre 1710 y 1747 , y, como la fuente principal de las calamidades sufridas por la ciudad son los informes de los funcionarios y las actas del Cabildo, cabe la posibilidad de que las mismas hayan sido en más de un momento exageradas para obtener recursos o atención por parte de las autoridades superiores. ${ }^{29}$

Sin embargo, la situación de guerra significó sin duda diversos problemas para la vida diaria de la ciudad. ${ }^{30}$ Como hemos mencionado, existió en ciertos momentos una constante sangría de población, tanto de la ciudad hacia otras más seguras, como de la campaña hacia la ciudad, llegando el caso de que sus habitantes tuvieron que abandonar de noche sus casas y recogerse en la zona céntrica. ${ }^{31}$ Durante mucho tiempo, las obras de defensa y las expediciones punitivas no dieron gran cosa; para 1723 Santa Fe se encontraba "en el último dintel de la más completa ruina", habiendo perdido todos los distritos que la circundaban, salvo uno, Coronda, que ese año fue atacado y comenzó también a despoblarse. Partidas indígenas asesinaban a los habitantes en pleno día y a las puertas mismas de la ciudad, y recorrían de noche sus calles, aullando a todo galope. Los diezmos

${ }^{27}$ Cervera, Historia, 1907, t. I, pp. 435 y ss., y Maeder, "Población”, 1976. Para 1710 se estimaba el consumo anual de ganado de la ciudad en 2000 cabezas, pero la cifra parece muy pequeña. Cervera, Historia, 1907, t. II, p. 98.

${ }^{28} \mathrm{El}$ obispo Peralta informaba que esas devastadoras incursiones contra Santa Fe "no se conocían antes de 1716". El padre Lozano, en 1733, decía que los golpes indígenas tenían "casi arruinada" a esa ciudad. Peralta al rey, s. 1., 1743, en Charlevoix, Histoire, 1756, t. VI, p. 86, y Lozano, Descripción, 1989, p. 94. La fecha exacta de inicio de los más cruentos ataques indígenas a Santa Fe es discutida; la mayoría de los historiadores la retrotrae a 1710, aunque otros la llevan a 1720. Alemán, Santa Fe, 1994, t. I, pp. 86 y ss.; Arenales, Noticias, 1833, p. 174, y Cervera, Historia, 1907 , t. I, pp. 425 y ss.

${ }^{29}$ Santa Fe fue declarada puerto preciso, es decir, punto de desembarque obligado de las mercancías que circulaban por el río Paraná, a fin de que oblaran allí impuestos. Esa ventaja le fue otorgada para darle la posibilidad de recaudar fondos para sostener la lucha contra los indígenas, y sólo le fue quitada en la década de 1780, cuando la amenaza de los aborígenes hacía mucho que era poco más que un recuerdo, y a pesar de que los vecinos destacados de la ciudad continuaban diciendo que les resultaba necesaria. Su supresión parece haber provocado de todos modos un fuerte impacto económico. Azara, Descripción, 1847, t. I, p. 335.

${ }^{30}$ Respecto de las condiciones del asedio, téngase en cuenta que sólo desde 1724 se resolvió cercar la ciudad con paredes y tapias de adobe, y dotarla de un foso; todo lo cual no impidió de todos modos que siguieran existiendo incursiones indígenas aun hasta el interior de ella. Cervera, Historia, 1907, t. I, pp. 461 y 481.

${ }^{31}$ Ibid., t. I, pp. 438 y ss. 
de la jurisdicción descendieron en picada; entre 1715 y 1731 oscilaban en cifras que iban de apenas 193 hasta 665 pesos. Téngase en cuenta que, una vez logradas las paces, subieron hasta más de $1000 .{ }^{32}$ Mejorando por momentos, sin embargo, a poco la situación volvía a ser crítica; el procurador del colegio jesuítico exponía su vida todas las semanas cuando iba a buscar los productos de la estancia conventual (situada a unos 200 kilómetros hacia el sur, en zona supuestamente segura) para traerlos a la ciudad..$^{33}$

¿Hasta qué punto las fluctuaciones de los precios locales reflejan las dificultades por las que pasó la economía santafesina en los años más álgidos de la lucha de fronteras contra los indígenas? ¿De qué forma esta afectó la provisión, y por consiguiente los precios, de los bienes de consumo básicos? La historiografía tradicional al respecto remarca la importancia de ese impacto, no sólo en el funcionamiento de los circuitos comerciales, sino en el mismo abasto cotidiano de la ciudad. Alemán, por ejemplo, insiste en que incluso las áreas de bosque más cercanas a la ciudad debieron ser abandonadas, por lo que esta dependía para sus alimentos de los cultivos y el ganado traídos desde la otra banda del Paraná, donde los colonos habían construido algunos asentamientos ayudados por relaciones más pacíficas con los indígenas de ese lugar. ${ }^{34}$ En todo caso, durante algunos años el asedio fue realmente duro; los fuertes que se construyeron fueron a menudo al poco tiempo destruidos, y las "entradas" que se efectuaron para "pacificar" a los indígenas no siempre lograron su cometido. Por lo demás, la contraofensiva criolla a partir de la década de 1740, que culminó con las paces generales del periodo 1747-1750, parece haber otorgado un alivio importante a la población local, implicando además avances amplios en la producción, que debía ahora no sólo surtir a la misma ciudad, sino también a las nuevas reducciones. ${ }^{35}$ En ese contexto, probablemente el retorno de vecinos anteriormente huidos, o la llegada de nuevos inmigrantes,

${ }^{32}$ Véanse los testimonios de los remates de los diezmos de los años 1715 a 1731 en AHPSF, Contaduría, t. 5, legs. 3 y 27, fs. 581, y los de 1750 en Archivo General de la Nación, Buenos Aires, Argentina (AGN), IX-13-3-3. Relato de los problemas de abasto en Cervera, Historia, 1907, t. I, pp. 443 y ss., y t. II, pp. 90 y ss.

${ }^{33}$ Paucke, Allá, 1942-1944, t. II, p. 7. La posición de la estancia, situada en San Miguel del Carcarañá, lejos de los frentes de guerra indígenas tanto del sur como del norte, le permitió conservar un importante stock de ganado, de entre 13000 y 18000 cabezas entre los años 1724 y 1741, además de alrededor de un centenar de esclavos. AHPSF, Contaduría, t. 6, 1707-1748 y 1733-1749, fs. 181 y ss.

${ }^{34}$ Alemán, Santa Fe, 1994, t. I, p. 85.

${ }^{35}$ Dobrizhoffer, Account, 1822, t. I, p. 102, recordaba que "[Santa Fe] En años anteriores cayó en la más extrema decadencia y se despobló a ojos vistas a causa de las incursiones de los bárbaros[...] Las estancias mejores y más distantes quedaron destruidas y en medio de la plaza y en pleno día se cometieron asesinatos. Por ello se dio la ordenanza de que ningún ciudadano fuera sin fusil a la iglesia. Al fin esta ciudad comenzó a reponerse desde que hubimos fundado las colonias de S. Javier, S. Jerónimo, Concepción y S. Pedro y S. Pablo y hubimos civilizado y hecho cristianos a los bárbaros." 
debió compensar las anteriores pérdidas poblacionales, originando una demanda adicional de bienes de consumo.

Es lógico así pensar que la situación de guerra quizá afectó las fluctuaciones de los precios en esa economía asediada. Ello reviste particular interés también desde la comparación que puede establecerse con las ciudades vecinas de Córdoba y Buenos Aires, donde los estudios disponibles han debatido largamente en torno a las tendencias de los precios, que parecen descender en forma moderada durante toda la primera mitad del siglo XVIII, quizá influenciados por el recorrido de sus similares europeos, pero divergiendo de estos al menos desde 1730. Estudiaremos entonces los precios santafesinos buscando tener en cuenta esos condicionantes.

\section{LA EVOLUCIÓN DE LOS PRECIOS DE LOS BIENES SEGÚN SU ORIGEN}

Las series de precios nominales obtenidas fueron agrupadas por origen. Se ponderó el peso de cada producto en cada serie y año, utilizándose la proporción del mismo en el monto total gastado. ${ }^{36}$ Luego se las llevó a números índice (base $1746=100$ ), cubriendo mediante interpolación lineal simple los faltantes. Véase resultado en la gráfica $1{ }^{37}$

Como puede observarse en la gráfica 1, la tendencia general es levemente declinante en el largo plazo (con la excepción relativa de los bienes ultramarinos en los últimos años), en especial a partir de inicios de la década de 1740, lo que, en primer lugar, confirma las tendencias cordobesas y porteñas, con un impacto quizá algo retrasado del progresivo aumento de precios europeos desde la década de $1730 .{ }^{38}$ Pero además, es probable que la evolución de los precios santafesinos esté también reflejando los efectos de la contraofensiva bélica criolla a partir de inicios de la década de 1740, y el proceso que culminará con la pacificación general.

De todos modos, la evolución de los precios se diferencia bastante según su origen. Los productos locales y regionales acusan una tendencia declinante más pronunciada al final del periodo, y una estabilidad general más marcada que la de los ultramarinos, circunstancia lógica dados los costos y problemas del transporte y la aleatoriedad relativa de los contac-

${ }^{36}$ Véanse las tablas de ponderación en el anexo.

${ }^{37}$ El año base 1746 fue elegido por ser bastante "normal": las fronteras se han estabilizado y las incursiones indígenas ya no son una amenaza constante; los contactos comerciales interiores son por tanto más fluidos. Si bien la guerra del Asiento (o de la oreja de Jenkins) no acabaría hasta 1748 , desde seis años antes las hostilidades en los mares son bastante poco intensas. Esto quizá explique los precios relativamente bajos de algunos bienes, tanto regionales como ultramarinos (yerba, ruán, lienzo), que no son, sin embargo, los más bajos de la serie (salvo en el caso de la ropa); o los valores intermedios de otros (trigo, aguardiente, papel).

${ }_{38}$ Arcondo, Ocaso, 1992, y Cuesta, Precios, 2009. 


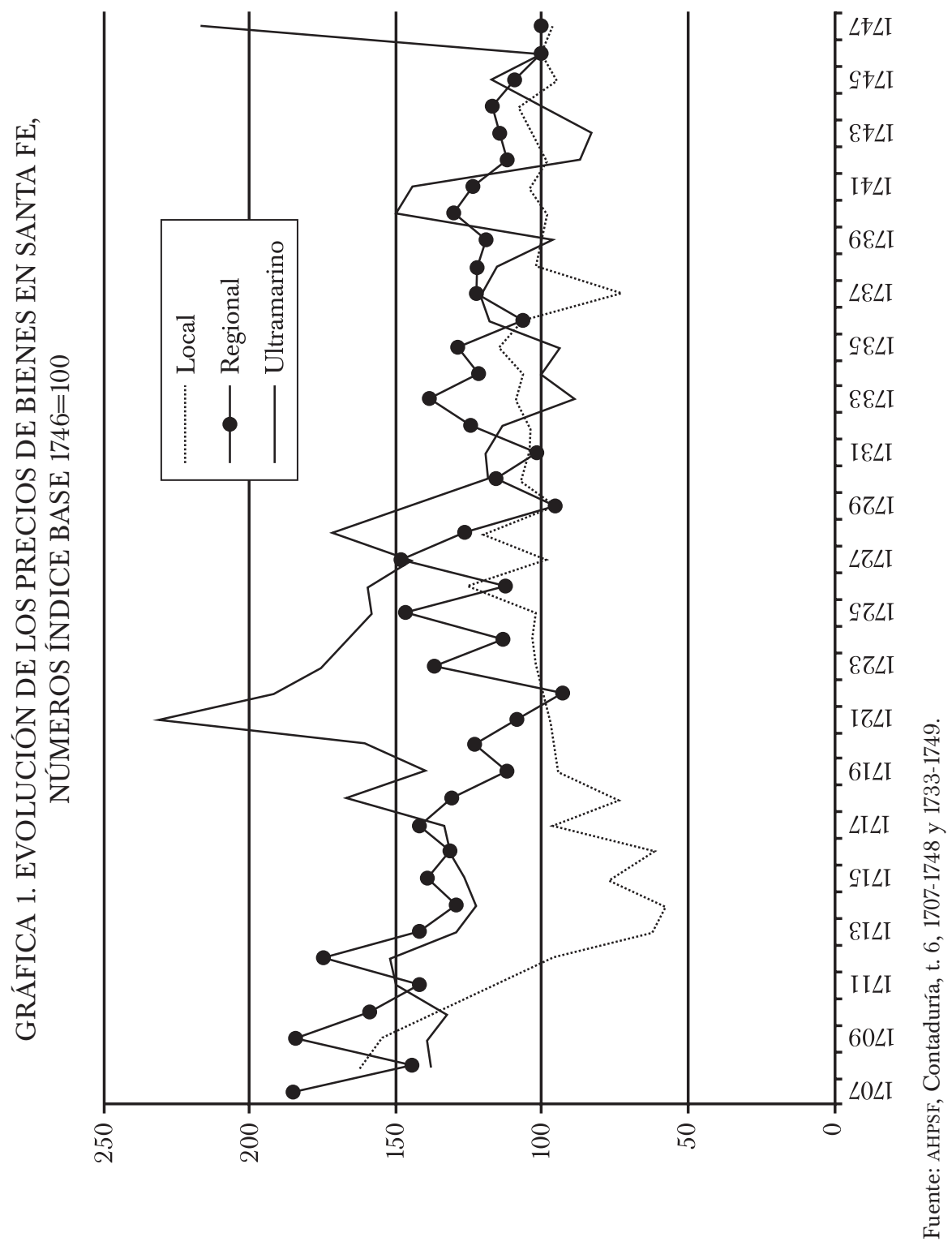


tos con Europa. Parece también evidente aquí una más lenta rotación de stocks y riesgos más altos, ligados obviamente a mayores tasas de ganancia. En todo caso, al analizar desagregadamente los bienes ultramarinos aparecen fuertes variaciones de un año a otro, y mientras algunos picos parecen coincidir con otros ciclos análogos en los bienes regionales o locales, la mayoría sigue una dinámica propia, como puede verse por ejemplo en la evolución inversa de los años 1721-1725, cuando los precios de los bienes ultramarinos aumentan fuertemente mientras que bajan los regionales, y 1732-1736, en que a un aumento progresivo de los precios de los bienes locales y regionales se contrapone un descenso en los correspondientes a los ultramarinos. ${ }^{39}$

Ello queda claramente evidenciado en la desviación estándar, que es mucho mayor en la serie de ultramarinos (24.77) que en la de productos locales (16.31), y en estos mayor que en la de productos regionales (12.04). No obstante, esa evolución aparentemente más armónica de los precios regionales oculta fuertes variaciones en momentos puntuales e incluso dentro de lapsos muy cortos (medibles en meses o aun semanas). Baste decir que, por ejemplo, la arroba de azúcar llega a costar en 1714, en promedio, más de $50 \%$ por sobre su precio de sólo cuatro años antes; y, con máximos de julio a diciembre en 64 reales, estos superaban en un tercio los valores de enero. De todos modos, resulta llamativo constatar que los bienes de origen regional (que sufrían las externalidades negativas de altos riesgos y costos de transporte) tienen una estabilidad un poco más marcada que los producidos en la misma Santa Fe (volatilidad entre máximos y mínimos absolutos de 64\%, mientras que la de los locales es de 71\%). Queda en evidencia entonces que resultaba mucho más riesgoso importar productos del exterior que de la región, y que incluso la producción de bienes locales sufría mayores distorsiones en sus precios que los regionales.

Es por demás sorprendente esta característica de los bienes regionales, más aún cuando, además del mencionado caso del azúcar, esta categoría incluía otros bienes con altas variaciones, como la yerba mate, que afectaban fuertemente la media (se han descartado los casos de yerba caaminí, la variedad más cotizada, figurando aquí sólo los de yerba de palos). Así, puede notarse en este caso un auge alcista entre 1732 y 1735 que la llevó a máximos de 28 reales y cuarto por arroba en agosto del último de esos años; pero, en 1729, había llegado a costar en promedio apenas unos ocho reales, precio al que habría de volver al final de nuestro periodo, cuando desde mayo de 1747 se derrumbe nuevamente. Ahora bien, de enero a

\footnotetext{
${ }^{39}$ Como es obvio y conocido, los bienes traídos de ultramar a América eran mucho más caros que en Europa. Los precios se quintuplicaban fácilmente entre uno y otro lados del Atlántico. Paucke, Allá, 1942-1944, t. I, p. 142, y Newland y Gallo, “Globalización”, 2004.
} 
marzo de ese año los precios que registra nuestra fuente son sustancialmente altos (22 a 24 reales), bajando en forma acelerada en las semanas siguientes hasta llegar, en junio, a menos de la tercera parte de ese valor, que se mantendrá hasta el inicio del siguiente año. Caídas similares se registraron entre 1717 y 1719 , seguidas de ascensos también sustantivos entre 1721 y 1725 . Si bien con algún pequeño desfase respecto a los precios santafesinos, Arcondo registró una evolución muy similar de este producto en su serie de Córdoba. ${ }^{40}$ Estas variaciones bruscas en productos agrarios son usuales en economías de base orgánica, sometidas a altas tasas de riesgo, altos y lentos costos de transporte, grandes pérdidas por almacenamiento y demanda inelástica y limitada en los puntos de consumo, que además en nuestro caso eran de dimensión muy débil. Pero aquí se suman problemas del lado de la oferta: las rebeliones comuneras en Paraguay, con momentos de durísimo conflicto que habrán de desorganizar la producción y provocar fuertes aumentos de precio, o descensos cuando aquella pudo recomponerse. Y también (aunque sus efectos sólo se verán en plenitud con el transcurrir del tiempo) cambios ligados a la decadencia relativa de las zonas mineras del Alto Perú como destino de este producto, y el ascenso de la ciudad de Buenos Aires, cuya población aumentará con rapidez desde mediados del siglo. ${ }^{41}$

Otros productos de esta categoría tienen, por su parte, un recorrido más uniforme sin dejar de variar a veces fuertemente. El tabaco, por ejemplo, tiene máximos de 45 reales por arroba en 1708, y, más allá de algunas caídas puntuales, la tendencia es homogéneamente decreciente hasta llegar a mínimos de 20 en 1747. Algo similar puede decirse del lienzo, que pasa de siete a cuatro reales por vara en ambas puntas de la serie. O de la ropa, que pasa de 8.5 reales por vara en 1708 a cuatro en 1747 . El resto de los bienes de origen regional muestra una estabilidad mucho mayor, por lo que su peso en el índice tiende a moderar sus fluctuaciones.

Dadas estas circunstancias, ¿qué fue lo que llevó a que los precios locales variaran con mayor amplitud? La explicación pasa básicamente por los precios del trigo. Resulta al respecto destacable la fuerte caída de 1709-1714, motivada entre 1709 y 1713 por el descenso de los precios de la harina y el trigo, y entre 1711 y 1714 por el de las vacas. Ambos fenómenos, pero especialmente el segundo, son contraintuitivos si pensamos en las condiciones de conflictividad bélica de esos años. Si bien debe destacarse que el precio del ganado se caracterizó luego de esa coyuntura por una

${ }^{40}$ Con mínimos de ocho reales por arroba en 1728-1729, alcanza máximos de 32 en 1734-1735.

${ }^{41}$ Sobre las rebeliones comuneras y sus efectos en la producción y comercio de la yerba véase Garavaglia, Mercado, 1983, pp. 79 y ss.; sobre los mercados de Potosí y Buenos Aires y el papel de Santa Fe, pp. 89 y ss. 
cierta estabilidad relativa (mucho más marcada en el caso de los precios de carneros y caballos que en el de las vacas), ello se contrapone con la robusta volatilidad en los precios del trigo, no sólo de un año a otro sino, como era de esperar, aun dentro de un mismo año. Así, por ejemplo, en mayo de 1708 se pagaron 58 reales por fanega, y en diciembre, en plena cosecha, 36; en febrero de 1717, 37 reales, y en agosto llegó a 72; o en enero de 1744, en que fueron 24 reales, mientras que en noviembre aumentó a $60 .{ }^{42}$ La harina, aun cuando sigue a menudo las variaciones del trigo, lo hace en forma mucho más mesurada, con periodos de estabilidad mayor. De todos modos, ambos productos pueden tener años bastante homogéneos: en 1712, por ejemplo, el trigo tuvo mínimos de 32 reales por fanega en febrero y máximos de 40 en septiembre; en 1725 la harina tuvo máximos de 64 reales por fanega en noviembre y mínimos de 48 en abril, es decir, en ambos casos una diferencia de entre 25 y 35\%. Nuevamente, algo parecido muestra Arcondo en su serie cordobesa. Sin embargo, en sus series los precios del vacuno son mucho más estables, con escalones de considerable magnitud (seis reales entre 1711 y 1715; ocho entre 1717 y 1724; 16 entre 1725 y 1730). Resulta así patente en Córdoba el efecto de la política de abasto administrada por el Cabildo; evidentemente en 1725 los regidores de esa ciudad decidieron reflejar un aumento de precios que ya se había ido manifestando en Santa Fe (entre 1720 y 1723 los precios de un vacuno pasan allí de 4.23 a 7.63 reales). ${ }^{43}$ Por lo tanto, la divergencia en esos años entre el aumento del precio del vacuno y el leve descenso relativo del precio de la grasa podría reflejar la respuesta de los abastecedores ante este aumento en el valor del vacuno, que debió implicar una mayor oferta local del producto. Es así que en Santa Fe los efectos de un precio administrado, si lo hubo, fueron de mucho menor impacto; tan sólo entre 1726-1727, 1729-1733 y desde 1735, los precios del vacuno pueden estabilizarse en torno a ocho reales por cabeza, aun cuando existan años intermedios con precios muy distintos. Pero es probable que esté pesando aquí un sesgo de la fuente: en tanto los jesuitas constituían algunos de los pocos grandes estancieros que contaban todavía con disponibilidad de ganado, posiblemente en esas ocasiones de gran carestía lo ofrecieran a la población a precios acordados con las autoridades. ${ }^{44}$ Eso explicaría que sólo en tres años, 1728, 1734 y 1743, haya superado los ocho reales por cabeza (y ello por un margen bastante magro).

${ }^{42}$ En la fuente aparece una partida de trigo importado desde Chile, que resultó más caro aún que la producción local, a pesar de encontrarse esta en época de escasez.

${ }_{43}$ Sobre el papel del Cabildo en la fijación de los precios del ganado en Córdoba, Arcondo, Ocaso, 1992, p. 141.

${ }^{44}$ Como ya se había hecho en 1714. Cervera, Historia, 1907, t. I, p. 437. 


\section{CUADRO 3. DESVIACIÓN ESTÁNDAR DE LOS PRECIOS DE TRIGO, YERBA Y PAPEL EN SANTA FE, CÓRDOBA Y BUENOS AIRES, $1707-1747^{\mathrm{a}}$}

\begin{tabular}{lccc}
\hline Producto & Santa Fe & Córdoba & Buenos Aires \\
Trigo & 9.76 & 7.03 & 11.25 \\
Yerba & 4.85 & 6.11 & s. d. \\
Papel & 9.98 & 11.48 & 4.43 \\
\hline
\end{tabular}

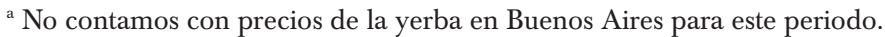

Fuentes: AHPSF, Contaduría, t. 6, 1707-1748 y 1733-1749; Arcondo, Ocaso, 1992, y Cuesta, Precios, 2009.

En resumen, podría postularse que el impacto de la situación bélica afectó a los precios locales y regionales sólo en ciertos momentos puntuales, pero que la caída de la conflictividad hacia el final del periodo analizado tendió a acentuar la tendencia decreciente de los precios, que había sufrido un impasse en el momento más álgido de la crisis, poniendo así a Santa Fe en línea con lo que ocurría en otras ciudades del entorno rioplatense.

Si bien la coyuntura de asedio de la economía santafesina es claramente la responsable de los fuertes vaivenes en los precios de los productos, vale la pena comparar, al menos en un producto de cada categoría de bienes (locales, regionales y ultramarinos), si la desviación estándar fue mayor que en las demás ciudades (véase cuadro 3).

Santa Fe y Córdoba comparten características -ya remarcadas anteriormente-, es decir, una mayor desviación en los productos locales y ultramarinos que en los regionales. No parece haber ocurrido esto en Buenos Aires, donde la desviación estándar del papel fue mucho más baja, lo cual parece ser lógico por ser Buenos Aires un centro importador directo de productos europeos, con evidentes beneficios en los costos de transacción y de transporte en relación con las ciudades del interior (hasta donde llegaban por tierra, es decir, en forma mucho más lenta, costosa y sujeta a riesgos). Sin embargo, el mercado de trigo parece haber sido allí un problema, seguramente debido a las dimensiones mismas de la ciudad, que la hacían más vulnerable a las crisis de abasto en caso de contingencias climáticas que afectaran las cosechas. Por su parte, las diferencias entre Santa Fe y Córdoba parecen explicarse por cuestiones geográficas: la yerba tiene en la primera un índice más alto que en Córdoba debido, seguramente, a las mayores distancias y por ende costos de flete (debe destacarse que hacia Santa Fe el transporte de yerba se hacía por vía fluvial desde las 
misiones del noreste). Algo similar ocurre con el papel, al que además del flete terrestre deben agregarse los costos ultramarinos. Esto da cuenta, en síntesis, de que la posición geográfica tuvo un fuerte impacto en la toma de riesgo y, por tanto, en la evolución de los precios.

\section{CONCLusiones}

Hemos intentado mostrar, a través de los datos provistos por una fuente de considerable riqueza, la evolución de la economía santafesina en un periodo en que, según la escasa bibliografía existente, había sido particularmente afectada por la guerra de fronteras. La fuente nos permitió elaborar series sistemáticas de seis productos locales, nueve regionales y tres ultramarinos para un espacio de vital importancia en los circuitos mercantiles del espacio rioplatense del siglo XVIII. Creemos que, en primer lugar, ha quedado demostrado que el impacto de la lucha de fronteras no tuvo, al menos en los precios, ni la dimensión ni la homogeneidad que suele adjudicársele en general a partir de la lectura de los informes y actas del Cabildo originados por las elites locales, deseosas quizá de magnificar los sufrimientos experimentados por la ciudad a fin de lograr para ella beneficios fiscales o el apoyo militar de sus vecinas. En todo caso, aun a pesar de la guerra de fronteras, el movimiento de los precios tendió a la baja, y las fluctuaciones, si bien muy pronunciadas en general y sobre todo en ciertas coyunturas, no parecen haber sido excesivamente afectadas por esa conflictividad. De modo que todo indicaría que la propia lógica del intercambio mercantil en esta economía de antiguo régimen, y en todo caso las alternativas climáticas, tuvieron mucho más peso que cualquiera otra circunstancia en la determinación del movimiento de los precios. Las características de esos mercados coloniales, segmentados, de demanda fuertemente inelástica, dependientes de información sesgada y aleatoria, servidos por medios de comunicación lentos y caros que entorpecían la fluidez del intercambio e introducían múltiples factores de riesgo, con baja rotación de stocks y grandes diferencias entre las distintas etapas de la cadena de formación de valor, han sido objeto de diversos estudios, y no podríamos detenernos en este artículo en su análisis. ${ }^{45}$ Pero de cualquier forma queremos dejar sentado el hecho ante la posible tendencia a sobredimensionar o al menos extrapolar el impacto de la situación de frontera y sus condicionantes en la oferta, cuando en realidad esta parece haber estado afectada en mucho mayor medida por elementos de condición estructural. Puede incluso enfatizarse el hecho de que la situación no era

${ }^{45}$ Véanse al respecto Silva, "Mercado”, 2010, pp. 33 y ss., y Garavaglia, Mercado, 1983. 
homogénea. Hemos visto que los precios de algunos productos locales podían resultar bastante afectados por la situación de guerra, o al menos en forma más intensa que otros, sobre todo de origen regional o ultramarino, cuyos precios se encontraban en cambio determinados por factores como la aleatoriedad, el costo y la tardanza de los transportes, antes que por la tasa diferencial de riesgo provocada por la belicosidad indígena. En todo caso, los precios locales tenían recorridos muy distintos según la misma los afectara en forma coyuntural o estructural: es decir, ciertos bienes como el ganado, objeto preferente de las expediciones de corso indígenas, resultaban mucho más estructuralmente afectados por la guerra que otros como el trigo, que sí podían verse perjudicados por ella, pero en los cuales, en el largo plazo, impactaban más intensamente otros factores.

De todos modos la imagen de una economía asediada se mantiene. Esto es, diversos indicios nos muestran que el riesgo incrementó sustantivamente los márgenes de incertidumbre y de escasez característicos de una economía orgánica que funcionaba dentro de un esquema mercantil de antiguo régimen. El descenso de la conflictividad de fronteras hacia la década de 1740 implicó también un descenso relativo de los índices de precios; si bien algo parecido se experimentó tanto en Buenos Aires como en Córdoba, todo parece indicar que la intensidad de la caída en Santa Fe fue mayor, al menos en lo que respecta a los precios locales. Un ejemplo útil lo tenemos en los correspondientes al ganado y a la grasa, pero podríamos ampliar el censo respectivo.

Por último, las variaciones de los precios de los productos regionales en la plaza santafesina no necesariamente estaban sólo vinculadas a las dificultades de transporte, comunicación o comercialización, sino que podían asimismo estar atadas a contingencias en origen. De cualquier forma, la menor volatilidad general de los precios de los bienes regionales puede también atribuirse, al menos en parte, al carácter de nudo comercial que poseía Santa Fe, que pudo primar por sobre su peso como centro de consumo.

Más allá de ello, este avance sobre la historia de precios en la etapa preestadística permitió un principio de comparación con otras plazas de considerable importancia en la época; el mismo será, en la medida de lo posible, profundizado más adelante. 
Anexo

CUADRO 1. PRECIOS DE BIENES. ${ }^{a}$ SANTA FE, 1707-1747

\begin{tabular}{|c|c|c|c|c|c|c|}
\hline \multirow[b]{2}{*}{$A \tilde{n} o$} & \multicolumn{3}{|c|}{ Precios $A$} & \multicolumn{3}{|c|}{ Precios $B$} \\
\hline & $\begin{array}{c}\text { Yerba } \\
\text { (arroba) }\end{array}$ & $\begin{array}{c}\text { Tabaco } \\
\text { (arroba) }\end{array}$ & $\begin{array}{c}\text { Vino } \\
\text { (botija) }\end{array}$ & $\begin{array}{l}\text { Lienzo } \\
\text { (varas) }\end{array}$ & $\begin{array}{l}\text { Ropa } \\
\text { (vara) }\end{array}$ & $\begin{array}{c}\text { Vacas } \\
\text { (unidad) }\end{array}$ \\
\hline 1707 & 18.40 & 40.00 & 124.80 & 7.00 & 7.75 & s. d. \\
\hline 1708 & 16.27 & 44.50 & 116.00 & 5.50 & 8.50 & s. d. \\
\hline 1709 & 16.00 & 40.00 & 123.52 & 3.54 & 8.33 & s. d. \\
\hline 1710 & 16.00 & 40.00 & 111.20 & 4.25 & 8.00 & s. d. \\
\hline 1711 & 16.00 & 37.59 & 118.18 & 6.00 & 8.00 & 8.00 \\
\hline 1712 & 16.00 & 32.22 & 111.50 & 6.21 & 8.00 & 4.25 \\
\hline 1713 & 16.50 & 32.33 & 107.67 & 6.33 & 7.85 & 4.07 \\
\hline 1714 & 16.00 & 27.57 & 102.55 & 6.04 & 7.20 & 4.01 \\
\hline 1715 & 16.00 & 39.33 & 104.25 & 6.00 & 8.00 & 5.28 \\
\hline 1716 & 16.00 & 33.33 & 104.00 & 5.50 & 8.00 & 4.37 \\
\hline 1717 & 15.77 & 36.20 & 106.30 & 6.06 & 8.00 & 4.54 \\
\hline 1718 & 13.81 & 33.14 & 105.55 & 6.00 & 6.25 & 4.13 \\
\hline 1719 & 8.00 & 32.00 & 130.67 & 5.24 & 5.34 & 4.00 \\
\hline 1720 & 8.49 & 29.51 & 116.91 & 4.40 & 5.88 & 4.23 \\
\hline 1721 & 8.00 & 30.00 & 116.00 & 5.15 & 6.12 & 6.20 \\
\hline 1722 & 9.33 & 27.46 & 131.71 & 6.00 & s. d. & 6.96 \\
\hline 1723 & 11.70 & 21.33 & 144.00 & 6.00 & 6.50 & 8.00 \\
\hline 1724 & 13.33 & 24.17 & 114.67 & 5.33 & 4.52 & 7.64 \\
\hline 1725 & 14.23 & 33.23 & 138.29 & 4.67 & 8.00 & 7.85 \\
\hline 1726 & 7.75 & 33.33 & 141.25 & 5.29 & 6.75 & 8.00 \\
\hline 1727 & 7.67 & 30.67 & 132.80 & 5.79 & 7.50 & 8.00 \\
\hline 1728 & 8.00 & 33.60 & 143.67 & 4.83 & 5.50 & 8.36 \\
\hline 1729 & 8.00 & 35.56 & 133.06 & 5.75 & 6.17 & 8.00 \\
\hline 1730 & 10.81 & 32.90 & 106.86 & 5.81 & 6.10 & 8.00 \\
\hline 1731 & 8.99 & 32.40 & 114.63 & 5.00 & 6.00 & 8.00 \\
\hline 1732 & 16.57 & 24.00 & 116.36 & 4.75 & 5.17 & 8.00 \\
\hline 1733 & 25.00 & 32.00 & 130.02 & 4.60 & 5.50 & 8.00 \\
\hline 1734 & 27.90 & 32.00 & 136.92 & 4.75 & 4.00 & 8.50 \\
\hline 1735 & 28.08 & 16.80 & 152.73 & 4.80 & 5.00 & 8.00 \\
\hline 1736 & 16.00 & 36.00 & 135.81 & 5.33 & 4.00 & 8.00 \\
\hline 1737 & 16.00 & 32.67 & 133.09 & 5.63 & 4.00 & 8.00 \\
\hline
\end{tabular}

${ }^{\text {a }}$ En reales de a ocho por un peso y 3.38 gramos del sistema métrico. 


\begin{tabular}{|c|c|c|c|c|c|c|}
\hline \multirow[b]{2}{*}{ Año } & \multicolumn{3}{|c|}{ Precios $A$} & \multicolumn{3}{|c|}{ Precios B } \\
\hline & $\begin{array}{c}\text { Yerba } \\
\text { (arroba) }\end{array}$ & $\begin{array}{c}\text { Tabaco } \\
\text { (arroba) }\end{array}$ & $\begin{array}{c}\text { Vino } \\
\text { (botija) }\end{array}$ & $\begin{array}{l}\text { Lienzo } \\
\text { (varas) }\end{array}$ & $\begin{array}{l}\text { Ropa } \\
\text { (vara) }\end{array}$ & $\begin{array}{c}\text { Vacas } \\
\text { (unidad) }\end{array}$ \\
\hline 1738 & 16.14 & 31.64 & 134.52 & 5.75 & 5.58 & 8.00 \\
\hline 1739 & 15.80 & 32.00 & 131.93 & 4.47 & 4.89 & 8.00 \\
\hline 1740 & 16.31 & 30.86 & 136.81 & 5.80 & 5.53 & 8.00 \\
\hline 1741 & 15.69 & 29.50 & 120.67 & 5.16 & 5.15 & 8.00 \\
\hline 1742 & 16.05 & 24.66 & 126.73 & 4.75 & 4.77 & 8.00 \\
\hline 1743 & 14.50 & 26.00 & 134.24 & 4.48 & 4.88 & 9.85 \\
\hline 1744 & 12.00 & 24.00 & 125.33 & 5.00 & 5.00 & 7.91 \\
\hline 1745 & 11.91 & 25.67 & 118.86 & 4.67 & 5.00 & 8.00 \\
\hline 1746 & 12.45 & 22.60 & 130.00 & 3.88 & 4.00 & 8.00 \\
\hline 1747 & 10.90 & 20.00 & 124.00 & 4.25 & 4.34 & 8.00 \\
\hline
\end{tabular}

CUADRO 2. PRECIOS DE BIENES. ${ }^{a}$ SANTA FE, 1707-1747

\begin{tabular}{|c|c|c|c|c|c|c|c|}
\hline \multirow[b]{2}{*}{$A \tilde{n} o$} & \multicolumn{4}{|c|}{ Precios $C$} & \multicolumn{3}{|c|}{ Precios D } \\
\hline & $\begin{array}{l}\text { Carneros } \\
\text { (unidad) }\end{array}$ & $\begin{array}{l}\text { Azúcar } \\
\text { (arroba) }\end{array}$ & $\begin{array}{c}\text { Trigo } \\
\text { (fanega) }\end{array}$ & $\begin{array}{c}\text { Grasa } \\
\text { (botija) }\end{array}$ & $\begin{array}{l}\text { Ruán } \\
\text { (vara) }\end{array}$ & $\begin{array}{l}\text { Harina } \\
\text { (fanega) }\end{array}$ & $\begin{array}{c}\text { Sal } \\
\text { (fanega) }\end{array}$ \\
\hline 1707 & s. d. & 49.33 & s. d. & s. d. & s. d. & s. d. & s. d. \\
\hline 1708 & s. d. & s. d. & 43.50 & s. d. & 8.20 & s. d. & 32.00 \\
\hline 1709 & s. d. & 40.00 & 41.33 & s. d. & 8.00 & 60.00 & s. d. \\
\hline 1710 & s. d. & 40.00 & 50.00 & s. d. & 8.00 & s. d. & 32.00 \\
\hline 1711 & s. d. & 41.75 & 37.48 & 48.00 & 11.50 & 40.80 & 32.00 \\
\hline 1712 & 7.85 & 43.20 & 33.05 & 40.00 & 10.00 & 40.00 & 32.00 \\
\hline 1713 & 8.00 & 56.00 & 24.80 & s. d. & s. d. & 24.00 & 24.00 \\
\hline 1714 & 8.00 & 58.67 & 25.80 & s. d. & 8.00 & s. d. & 32.80 \\
\hline 1715 & 8.00 & 40.00 & s. d. & s. d. & 8.00 & s. d. & 28.00 \\
\hline 1716 & 8.00 & 40.00 & s. d. & s. d. & 8.00 & s. d. & s. d. \\
\hline 1717 & 8.00 & 36.00 & 54.50 & 48.00 & s. d. & s. d. & 28.00 \\
\hline 1718 & 8.00 & 32.00 & 34.50 & 52.00 & 10.00 & s. d. & 30.00 \\
\hline 1719 & 8.00 & 36.00 & 24.00 & s. d. & 8.50 & s. d. & 32.00 \\
\hline 1720 & 8.00 & 40.00 & 29.33 & 48.00 & s. d. & s. d. & s. d. \\
\hline 1721 & 8.00 & 40.00 & 34.00 & 48.00 & 14.00 & s. d. & 33.00 \\
\hline 1722 & 8.00 & 44.67 & s. d. & 48.00 & 11.50 & s. d. & 33.13 \\
\hline 1723 & 8.00 & 37.60 & 28.13 & s. d. & s. d. & s. d. & 32.00 \\
\hline 1724 & 8.00 & 40.00 & 32.00 & 44.00 & s. d. & 48.00 & s. d. \\
\hline
\end{tabular}

${ }^{\text {a }}$ En reales de a ocho por un peso y 3.38 gramos del sistema métrico. 


\begin{tabular}{|c|c|c|c|c|c|c|c|}
\hline \multirow[b]{2}{*}{$A \tilde{n} o$} & \multicolumn{4}{|c|}{ Precios $C$} & \multicolumn{3}{|c|}{ Precios D } \\
\hline & $\begin{array}{l}\text { Carneros } \\
\text { (unidad) }\end{array}$ & $\begin{array}{l}\text { Azúcar } \\
\text { (arroba) }\end{array}$ & $\begin{array}{c}\text { Trigo } \\
\text { (fanega) }\end{array}$ & $\begin{array}{c}\text { Grasa } \\
\text { (botija) }\end{array}$ & $\begin{array}{l}\text { Ruán } \\
\text { (vara) }\end{array}$ & $\begin{array}{l}\text { Harina } \\
\text { (fanega) }\end{array}$ & $\begin{array}{c}\text { Sal } \\
\text { (fanega) }\end{array}$ \\
\hline 1725 & 8.00 & 40.00 & s. d. & 48.00 & 12.00 & 56.00 & s. d. \\
\hline 1726 & 6.67 & 35.20 & s. d. & 48.00 & 11.40 & 54.00 & 36.00 \\
\hline 1727 & s. d. & 32.00 & 16.00 & 48.00 & 9.00 & 49.37 & 48.00 \\
\hline 1728 & 7.75 & 40.30 & 24.00 & 48.00 & 12.40 & 48.00 & 48.00 \\
\hline 1729 & 8.00 & 34.29 & 16.00 & 49.45 & 9.30 & 48.00 & 48.00 \\
\hline 1730 & 8.00 & 40.38 & s. d. & 47.00 & 8.00 & 47.51 & 48.00 \\
\hline 1731 & 8.00 & 32.00 & 20.00 & 48.00 & 8.00 & 48.00 & 48.00 \\
\hline 1732 & 8.00 & 32.00 & 24.00 & 48.00 & 8.00 & 48.00 & 40.00 \\
\hline 1733 & 8.00 & 32.00 & 24.00 & 32.33 & 6.00 & 48.00 & 24.00 \\
\hline 1734 & 8.00 & 36.22 & 16.00 & 45.67 & s. d. & 47.33 & 48.00 \\
\hline 1735 & 8.00 & 35.33 & s. d. & 48.00 & 6.00 & 48.00 & 53.33 \\
\hline 1736 & 8.00 & 37.50 & 24.00 & 48.00 & 7.33 & 47.00 & 28.00 \\
\hline 1737 & 8.00 & 38.40 & 16.00 & 48.00 & 7.50 & 33.78 & 34.67 \\
\hline 1738 & 8.00 & 36.00 & s. d. & 48.00 & 8.00 & 32.18 & 37.33 \\
\hline 1739 & 8.00 & 38.30 & 17.50 & 36.00 & 8.50 & 32.31 & 40.00 \\
\hline 1740 & 8.00 & 33.88 & 18.67 & 34.67 & 9.00 & 31.40 & 44.00 \\
\hline 1741 & 7.10 & 37.60 & 22.67 & 36.00 & 10.00 & 32.00 & 41.60 \\
\hline 1742 & 6.68 & 35.65 & 20.00 & 36.00 & s. d. & 32.00 & 44.00 \\
\hline 1743 & 3.80 & 38.50 & 24.00 & 32.00 & s. d. & 32.89 & 40.00 \\
\hline 1744 & s. d. & 48.00 & 36.00 & 40.00 & s. d. & 31.00 & s. d. \\
\hline 1745 & s. d. & 33.60 & 24.00 & 33.25 & 5.75 & 32.00 & 40.00 \\
\hline 1746 & 4.00 & 25.45 & 27.00 & 32.00 & 6.00 & 30.04 & 44.00 \\
\hline 1747 & 3.33 & 32.00 & 24.00 & 32.00 & 13.00 & 30.00 & 40.00 \\
\hline
\end{tabular}

\section{CUADRO 3. PRECIOS DE BIENES. ${ }^{a}$ SANTA FE, 1707-1747}

\begin{tabular}{lccccc}
\hline Año & $\begin{array}{c}\text { Cera de Santiago } \\
\text { (libra) }\end{array}$ & $\begin{array}{c}\text { Bayeta } \\
\text { (vara) }\end{array}$ & $\begin{array}{c}\text { Precios } E \\
\text { Caballos } \\
\text { (unidad) }\end{array}$ & $\begin{array}{c}\text { Aguardiente } \\
\text { (botija) }\end{array}$ & $\begin{array}{c}\text { Papel } \\
\text { (resma) }\end{array}$ \\
1707 & s. d. & s. d. & s.d. & s. d. & s. d. \\
1708 & 8.00 & 8.39 & s.d. & 112.00 & s. d. \\
1709 & 8.00 & 8.40 & 16.00 & s. d. & s. d. \\
1710 & 8.00 & 8.00 & 16.00 & 200.00 & 28.00 \\
1711 & 8.00 & 8.00 & 15.93 & 200.00 & 40.00
\end{tabular}

${ }^{\text {a }}$ En reales de a ocho por un peso y 3.38 gramos del sistema métrico. 


\begin{tabular}{|c|c|c|c|c|c|}
\hline Año & $\begin{array}{c}\text { Cera de Santiago } \\
\text { (libra) }\end{array}$ & $\begin{array}{r}\text { Bayeta } \\
\text { (vara) }\end{array}$ & $\begin{array}{l}\text { Caballos } \\
\text { (unidad) }\end{array}$ & $\begin{array}{c}\text { Aguardiente } \\
\text { (botija) }\end{array}$ & $\begin{array}{l}\text { Papel } \\
\text { (resma) }\end{array}$ \\
\hline 1712 & 8.00 & 7.71 & 15.88 & s. d. & 40.00 \\
\hline 1711 & 8.00 & 8.00 & 15.93 & 200.00 & 40.00 \\
\hline 1712 & 8.00 & 7.71 & 15.88 & s. d. & 40.00 \\
\hline 1713 & 8.00 & 8.00 & 16.00 & s. d. & 40.00 \\
\hline 1714 & 8.00 & 7.00 & 16.00 & s. d. & 34.67 \\
\hline 1715 & 8.00 & 8.00 & 16.00 & 144.00 & 40.00 \\
\hline 1716 & 8.00 & 8.00 & 16.00 & s. d. & 24.00 \\
\hline 1717 & 8.00 & 8.00 & 16.00 & s. d. & s. d. \\
\hline 1718 & 8.00 & s. d. & 16.00 & 144.00 & s. d. \\
\hline 1719 & 8.00 & 5.00 & 16.00 & 272.00 & s. d. \\
\hline 1720 & 8.00 & s. d. & 16.00 & 208.00 & 64.00 \\
\hline 1721 & 8.00 & 6.00 & s. d. & s. d. & s. d. \\
\hline 1722 & s. d. & s. d. & 16.00 & 192.00 & s. d. \\
\hline 1723 & 8.00 & s. d. & 16.00 & 192.00 & s. d. \\
\hline 1724 & 8.00 & s. d. & 16.00 & 196.00 & s. d. \\
\hline 1725 & s. d. & 8.00 & 16.00 & 240.00 & s. d. \\
\hline 1726 & 8.00 & 8.00 & s. d. & 160.00 & 32.00 \\
\hline 1727 & s. d. & 8.00 & s. d. & 224.00 & 64.00 \\
\hline 1728 & s. d. & 8.00 & s. d. & 170.67 & 32.00 \\
\hline 1729 & 8.00 & 7.00 & s. d. & 128.00 & 44.00 \\
\hline 1730 & s. d. & s. d. & 16.00 & 192.00 & 37.33 \\
\hline 1731 & 8.00 & s. d. & s. d. & 181.33 & 30.00 \\
\hline 1732 & 7.67 & s. d. & 15.00 & 176.00 & 28.00 \\
\hline 1733 & 7.60 & s. d. & s. d. & 160.00 & 32.00 \\
\hline 1734 & 7.00 & 6.00 & 16.00 & s. d. & s. d. \\
\hline 1735 & s. d. & s. d. & 16.00 & 184.00 & 32.00 \\
\hline 1736 & 8.00 & s. d. & s. d. & 160.00 & 36.00 \\
\hline 1737 & s. d. & s. d. & s. d. & s. d. & 36.00 \\
\hline 1738 & 8.00 & s. d. & 16.00 & 200.00 & 32.00 \\
\hline 1739 & 6.00 & 5.00 & 16.00 & 144.00 & 26.00 \\
\hline 1740 & 6.83 & s. d. & 16.00 & s. d. & s. d. \\
\hline 1741 & 5.20 & 5.00 & s. d. & 176.00 & s. d. \\
\hline 1742 & 6.60 & 5.25 & s. d. & 160.00 & 32.00 \\
\hline 1743 & 6.50 & 5.00 & 8.00 & s. d. & s. d. \\
\hline 1744 & 7.00 & s. d. & s. d. & s. d. & s. d. \\
\hline 1745 & 6.00 & 12.50 & 12.25 & s. d. & 46.00 \\
\hline 1746 & 7.13 & 6.00 & 16.00 & 176.00 & 40.00 \\
\hline 1747 & 8.00 & s. d. & s. d. & s. d. & s. d. \\
\hline
\end{tabular}


点

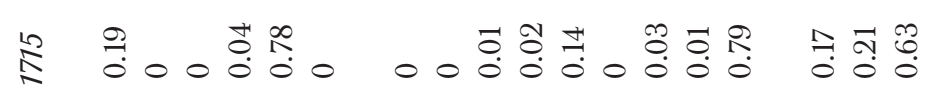

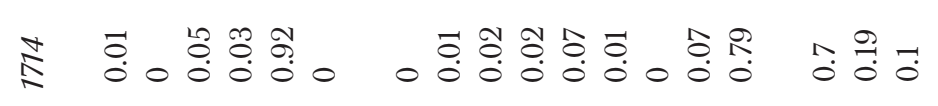

叙

容

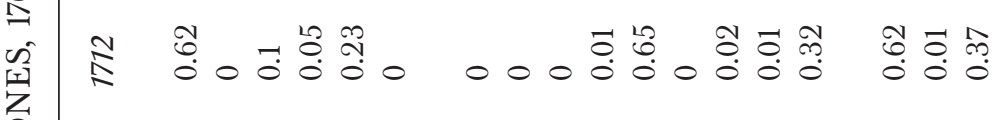

尊 正

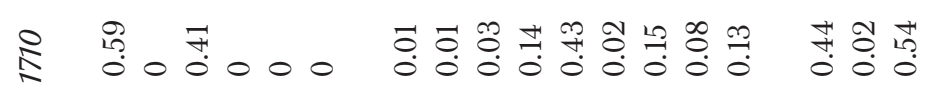

里

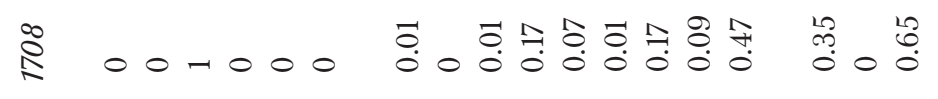

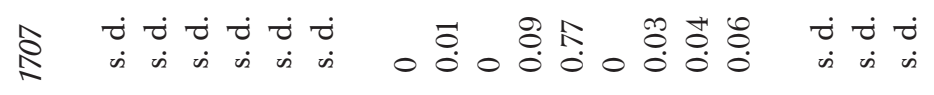

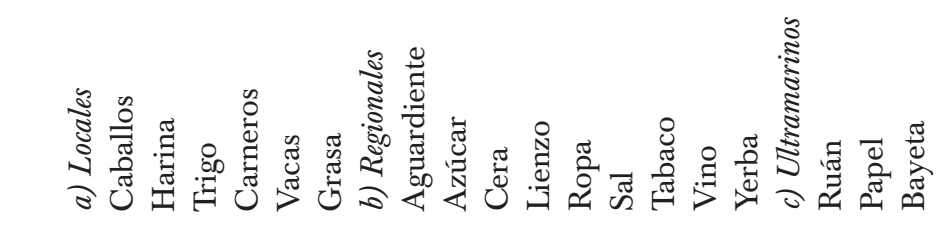


佥 0 ปั 咅 0 ○ 蛋 芝

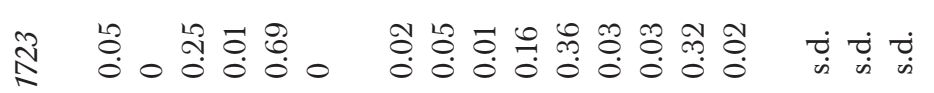
농

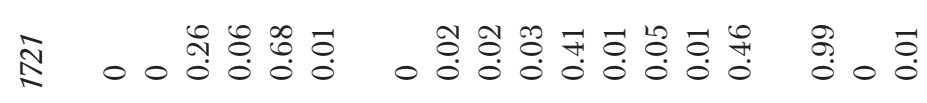

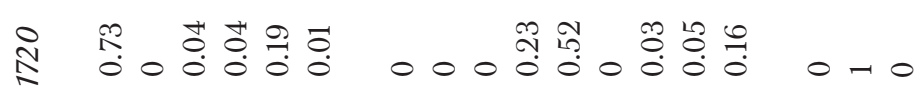
尽

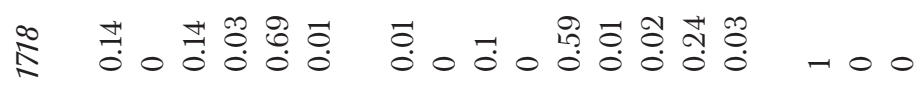
点

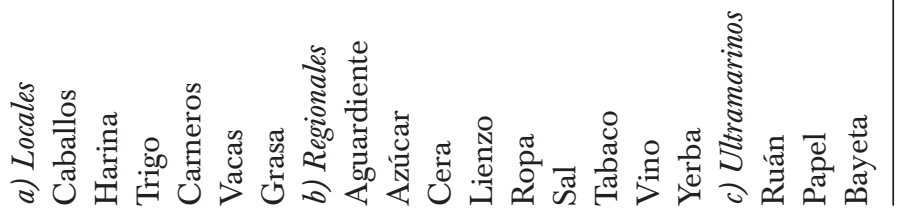




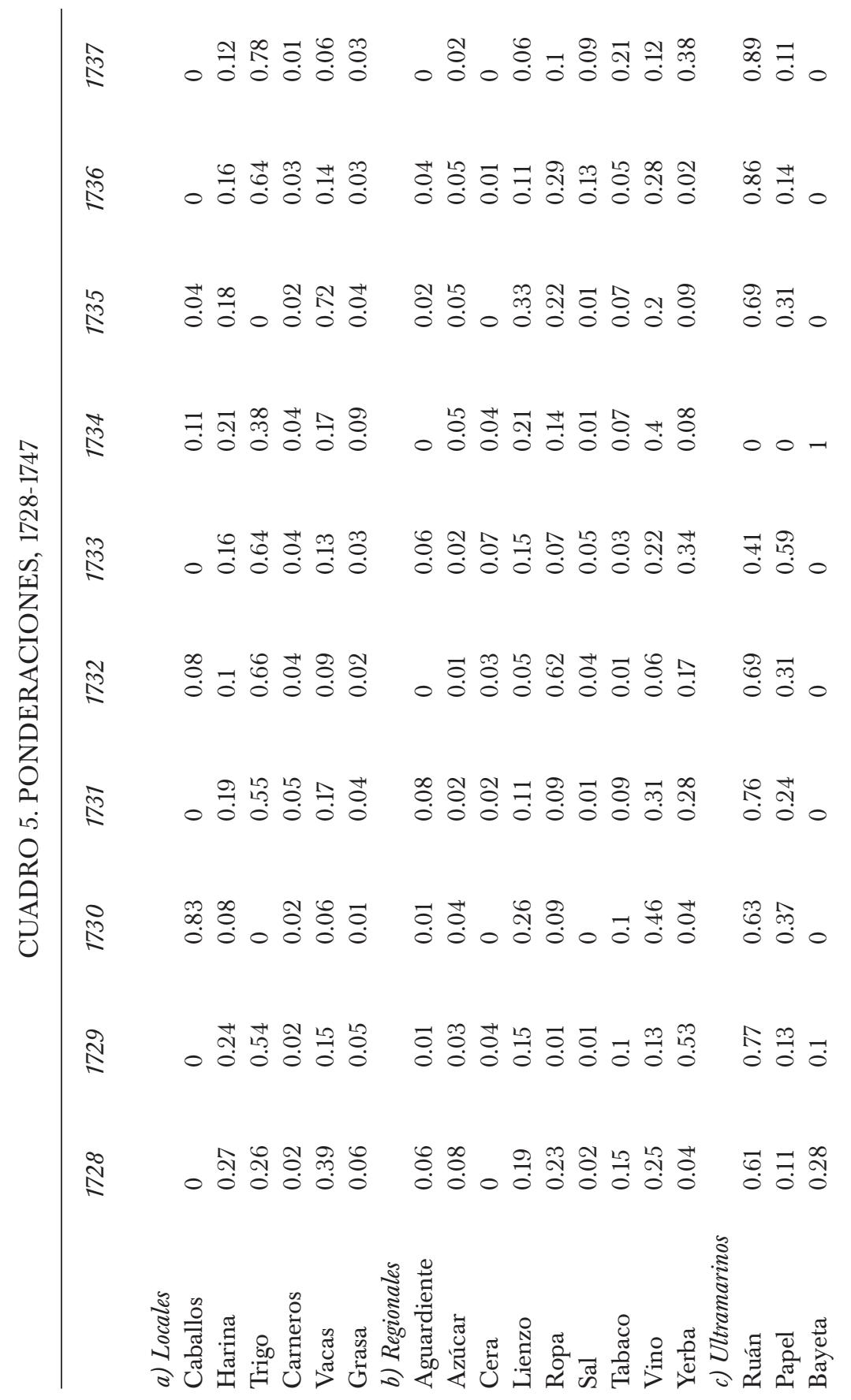


专

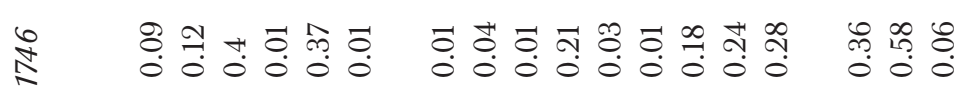

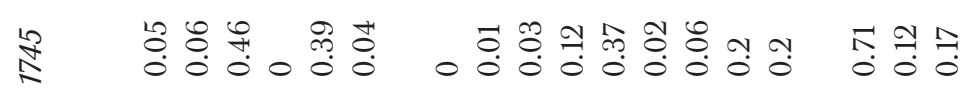

赤

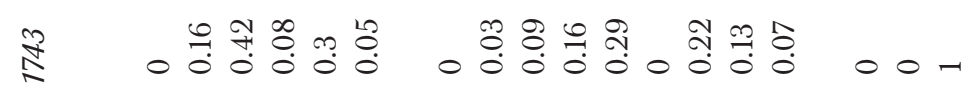

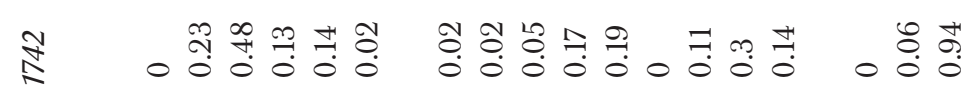

专

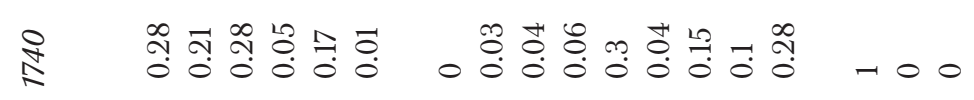

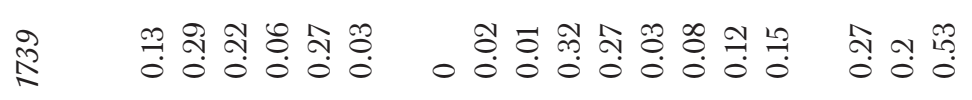

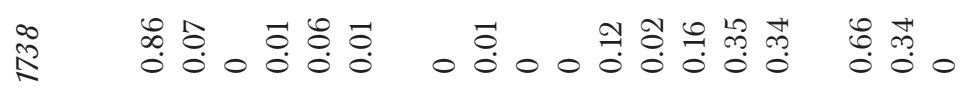

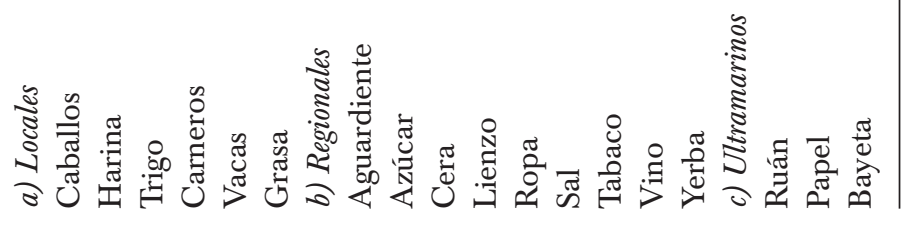




\section{FUENTES CONSULTADAS}

\section{Archivos}

AGN Archivo General de la Nación, Buenos Aires, Argentina.

AHPSF Archivo Histórico de la Provincia de Santa Fe, Santa Fe, Argentina.

AOLM Archivo de la Orden de La Merced, Córdoba, Argentina.

\section{Bibliografía}

Alemán, Bernardo, Santa Fe y sus aborígenes, Santa Fe, Junta Provincial de Estudios Históricos, 1994.

Allen, Robert C. et al., "Wages, Prices, and Living Standards in China, Japan, and Europe, 1738-1925”, The Economic History Review, núm. 64, suplemento 1, 2011, pp. 8-38, 2011, <http://www.nuff.ox.ac.uk/ users/ allen/ unpublished/ fiveauthorjehrev.pdf $>$. [Consulta: octubre de 2011.]

Álvarez, JuAn, Temas de historia económica argentina, Buenos Aires, El Ateneo, 1929.

Arcondo, Aníbal, El ocaso de una sociedad estamental. Córdoba entre 1700 y 1760, Córdoba, Universidad Nacional de Córdoba, 1992.

Ardissone, RomuldDo, Datos históricos acerca de las precipitaciones pluviales en la zona de Buenos Aires desde el siglo XVI hasta 1821, Buenos Aires, Imprenta y Casa Editora Coni, 1937.

Arenales, José I., Noticias históricas y descriptivas sobre el gran país del Chaco y río Bermejo, Buenos Aires, Hallet y Cía., 1833.

AzARA, FÉLIX DE, Voyages dans l'Amérique Méridionale, par... Commissaire et Commandant des limites espagnoles dans le Paraguay depus 1781 jusqu'en 1801..., París, Dentu, 1809. , Descripción e historia del Paraguay y del Río de la Plata, Madrid, Imprenta de Sanchiz, 1847.

Broadberry, Stephen y Bishnupriya Gupta, “The Early Modern great Divergence: Wages, Prices and Economic Development in Europe and Asia, 1500-1800”, Centre for Economic Policy Research Discussion Papers, núm. 4947, Londres, Centre for Economic Policy Research, 2005.

Burzio, Humberto, Diccionario de la moneda hispanoamericana, Santiago de Chile, Fondo Histórico y Bibliográfico José Toribio Medina, 1958.

Carrara, Angelo, "Para uma historia dos preços do periodo colonial: questoês de método", Locus, Universidad Federal de Juiz de Fora, vol. 14, núm. 1, 2008, Minas Gerais, pp. 163-194.

Cervera, Manuel, Historia de la ciudad y provincia de Santa Fe, Santa Fe, Librería y Encuadernación La Unión, 1907. 
Charlevoix, Pierre F. X. DE, Histoire du Paraguay, Paris, Ganeau-Bauche-D'Houry, 1756.

COMADRÁn RuIZ, JORGE, Evolución demográfica argentina durante el periodo hispano (15351810), Buenos Aires, Editorial Universitaria de Buenos Aires, 1969.

Cuesta, Martín, Precios, población, impuestos y producción. La economía de Buenos Aires en el siglo XVIII, Buenos Aires, Temas, 2009.

DJenderedjian, Julio, "Una reevaluación del peonaje por deudas. El caso de la producción yerbatera paraguaya a inicios del siglo XIX”, Boletín del Instituto de Historia Argentina y Americana Dr. Emilio Ravignani, Instituto Ravignani, núms. 16-17, 3a. serie, 1998, pp. 85-122.

Dobado, Rafael y Héctor García Montero, "Neither so Low nor so Short: Wages and Heights in Bourbon Spanish America from an International Comparative Perspective", Working Papers in Economic History, European Historical Economics Society, núm. 14, febrero de 2012.

Dobrizhoffer, Martin, An account of the Abipones, an equestrian people of Paraguay, Londres, John Murray, 1822.

Engerman, S. y H. Klein, "Prices as a Tool of Historical Analysis", América Latina en la Historia Económica, Instituto de Investigaciones Dr. José María Luis Mora, núm. 5, 1996, México, pp. 9-19.

Garavaglia, Juan C., Mercado interno y economía colonial, México, Grijalbo, 1983. "Precios de los productos rurales y precios de la tierra en la campaña de Buenos Aires: 1750-1826", Boletín del Instituto de Historia Argentina y Americana Dr. Emilio Ravignani, Instituto Ravignani núm. 11, 3a. serie, 1995, Buenos Aires, pp. 65-112.

Hoffman, PhiliP et al., "Real Inequality in Europe since 1500", The Journal of Economic History, The Economic History Association, núm. 62, 2002, pp. 322-255.

Johnson, Lyman, "Salarios, precios y costo de vida en el Buenos Aires colonial tardío", Boletín del Instituto de Historia Argentina y Americana Dr. Emilio Ravignani, Instituto Ravignani, núm. 2, 3a. serie, 1990, Buenos Aires, pp. 133-157.

Llopis, EnRIQUe y HÉCTOR García, "Cost of Living and Wages in Madrid, 16801800" en The Seventh European Historical Economics Society Conference, Lund, Suecia, 2007, pp. 1-53.

LLOPIS, ENRIQUE y SONIA SOTOCA, "Antes, bastante antes: la primera fase de la integración del mercado español de trigo, 1725-1726-1807-1808”, Historia Agraria. Revista de Agricultura e Historia Rural, Sociedad Española de Historia Agraria/Universidad de Murcia, núm. 36, 2005, pp. 225-262.

Lozano, Pedro, Descripción corográfica del Gran Chaco Gualamba, Tucumán, Universidad Nacional de Tucumán, 1989.

Maeder, Ernesto J. A., "La población del litoral argentino según la breve relación geográfica y política del la Gobernación del Río de la Plata (1760)", Folia Histórica del Nordeste, Universidad Nacional del Nordeste, núm. 2, 1976, Argentina, pp. 129-176. 
Napp, Ricardo, La República Argentina, Buenos Aires, Sociedad Anónima, 1876.

Newland, Carlos y Andrés Gallo, "Globalización y convergencia de precios en el imperio español, 1660-1810”, Revista de Historia Económica, Journal of Iberian and Latin American Economic History, Instituto Figuerola de Historia Económica, Universidad Carlos III de Madrid, vol. XXII, núm. 3, 2004, Madrid, pp. 573-596.

Nordhaus, William, "Do Real-Output and Real-Wage Measures Capture Reality? The History of Lighting Suggests Not" en Timothy F. Bresnahan y Robert J. Gordon (eds.), The Economics of New Goods, Chicago, University of Chicago Press, 1996.

Paucke, Florian, Hacia allá y para acá. Una estada entre los indios mocobíes, 1749-1767, Tucumán-Buenos Aires, Universidad Nacional de Tucumán, 1942-1944.

Pérez Colman, CÉSAR, La parroquia y la ciudad de Paraná en su segundo centenario. 1730 1930, Paraná, Talleres Gráficos La Acción, 1930.

Romano, Ruggiero, Moneda, seudomonedas y circulación monetaria en las economías de México, México, Fondo de Cultura Económica, 1998.

Silva Riquer, Jorge, "El mercado interno colonial novohispano. Siglos XVI-XIX. Evidencias y resultados", Economía y Sociedad, Universidad Michoacana de San Nicolás de Hidalgo, vol. XIV, núm. 25, enero-junio, 2010, México, pp. 33-50.

Suárez, Teresa y María Laura Tornay, "Poblaciones, vecinos y fronteras rioplatenses. Santa Fe a fines del siglo XVIII”, Anuario de Estudios Americanos, Escuela de Estudios Hispano-Americanos, vol. XL, núm. 2, 2003, España, pp. 521-555.

Telesca, Ignacio, Tras los Expulsos. Cambios demográficos y territoriales en el Paraguay después de la expulsión de los jesuitas, Asunción, Universidad Católica, 2009.

VRIES, JAN DE, "Between Purchasing Power and the World of Goods: Understanding the Household Economy in Early Modern Europe" en John Brewer y RoY PorTER (eds.), Consumption and the World of Goods, Londres, Routledge, 1993. 